\title{
Multiple introductions of divergent genetic lineages in an invasive fungal pathogen, Cryphonectria parasitica, in France
}

\author{
C Dutech, O Fabreguettes, X Capdevielle and C Robin \\ INRA, UMR 1202 BIOGECO, Equipe de Pathologie Forestière, Domaine de Pierroton, Cestas, France
}

\begin{abstract}
The occurrence of multiple introductions may be a crucial factor in the successful establishment of invasive species, but few studies focus on the introduction of fungal pathogens, despite their significant effect on invaded habitats. Although Cryphonectria parasitica, the chestnut blight fungus introduced in North America and Europe from Asia during the 20th century, caused dramatic changes in its new range, the history of its introduction is not well retraced in Europe. Using 10 microsatellite loci, we investigated the genetic diversity of 583 isolates in France, where several introductions have been hypothesized. Our analyses showed that the seven most frequent multilocus genotypes belonged to three genetic lineages, which had a
\end{abstract}

different and geographically limited distribution. These results suggest that different introduction events occurred in France. Genetic recombination was low among these lineages, despite the presence of the two mating types in each chestnut stand analysed. The spatial distribution of lineages suggests that the history of introductions in France associated with the slow expansion of the disease has contributed to the low observed rate of recombination among the divergent lineages. However, we discuss the possibility that environmental conditions or viral interactions could locally reduce recombination among genotypes. Heredity (2010) 105, 220-228; doi:10.1038/hdy.2009.164; published online 9 December 2009

Keywords: Ascomycota; Bayesian clustering analysis; biological invasion; Cryphonectria-Hypovirus; linkage disequilibrium; principal component analysis

\section{Introduction}

Although fungal plant pathogens represent a significant proportion of invasive species worldwide, and can have huge impact on ecosystems (Desprez-Loustau et al., 2007), few studies have focused on the evolutionary mechanisms that explain their success of invasion (for example Dlugosch and Parker, 2008). In plant invasive species for which evolutionary processes have been intensively studied, multiple introductions could be critical for establishment in the areas of introduction (Novak, 2007; Dlugosch and Parker, 2008). In particular, multiple introductions may favour admixture of genetic pools from original genetically differentiated populations and allow the emergence of new genotypes that may be well adapted to the new habitat (for example Facon et al., 2005; Lavergne and Molofsky, 2007). In fungal plant pathogens, several examples of multiple introductions have been reported (for example Stukenbrock et al., 2006; Delmotte et al., 2008; Goss et al., 2009), but successful invasions would have also occurred from single clonal lineages (for example Goodwin et al., 1994; Engelbrecht et al., 2004; Raboin et al., 2007). Finally, the number of studies clearly documenting the history of introduction (that is number of introductions, introduced

Correspondence: Dr C Dutech, INRA, UMR 1202 BIOGECO, Equipe de Pathologie Forestière, Domaine de Pierroton, Cestas cedex F-33612, France. E-mail: cyril.dutech@pierroton.inra.fr

Received 9 July 2009; revised 19 October 2009; accepted 22 October 2009; published online 9 December 2009 genetic diversity and evolutionary processes) is too low to evaluate the statement: 'multiple introductions is the rule rather than the exception' as has been proposed for plant species (Novak, 2007).

Another question associated with introduction is to determine whether genetic recombination among different introduced genotypes or genetic pools is frequent or not during the second phase of invasion. As fungal pathogens can generally reproduce asexually, clonal expansion can be the main mode of reproduction during colonization of the areas of introduction limiting recombination among genotypes (see for example Milgroom et al., 2008). On one hand, asexual reproduction provides the possibility of reproducing with a single founding genotype, in the absence of a compatible mating type, or climatic conditions conducive for sexual reproduction (that is sexual failure; Silvertown, 2008). On the other hand, because of pre-adaptation, high plasticity or high mutation rates, few clonal lineages may be well adapted to the new environment and able to rapidly expand in the new area of introduction (that is clonal success; Silvertown, 2008). Furthermore, admixture among differentiated genetic pools may sometimes be disadvantageous because it would disrupt adaptative genetic combination (Barton, 2001; Cornman et al., 2004). Increasing the number of studies focusing on modes of reproduction and the importance of recombination events among founding genotypes is important to understand adaptation of invasive fungal plant pathogens to new hosts and new areas. 
The chestnut blight fungus (Cryphonectria parasitica), an ascomycete infecting the cork and the cambial area of its host, is a prominent example of an invasive plant fungal pathogen that has had a dramatic impact in its introduced range (Anagnostakis, 1987). Meanwhile, the history of its spread has not been completely retraced. In North America, where C. parasitica was first reported in 1904, the pathogen almost caused the extinction of the American chestnut (Castanea dentata) in its native area. In Europe, strong economic losses and high mortality rates have been observed on European chestnut (C. sativa) since the first report of the pathogen in 1938 in northern Italy (Biraghi, 1946) and in France in 1956 (Grente, 1981). In both continents, the genetic diversity of $C$. parasitica populations seemed lower than in Japan and China, the native area of $C$. parasitica (for example Liu and Milgroom, 2007). Although the recent analysis of South-Eastern European populations showed a clonal expansion of C. parasitica likely from Italy (Milgroom et al., 2008), genetic analyses of populations from the Atlantic part of Europe suggested that other populations genetically divergent from Italian populations could have been introduced and would spread clonally (Breuillin et al., 2006; Braganca et al., 2007; Montenegro et al., 2008; Robin et al., 2009). However, in contrast to Eastern European populations in which only one mating was generally detected (Milgroom et al., 2008), in these Western populations both mating types were often found allowing sexual reproduction among isolates in this heterothallic haploid species (Braganca et al., 2007; Dutech et al., 2008; Robin et al., 2009). The studies in the Atlantic part of Europe were performed with phenotypic markers for which the genetic determinants have not been completely elucidated (that is vegetative compatible (vc) types; Robin et al., 2000; Braganca et al., 2007; Montenegro et al., 2008; Robin et al., 2009) or with molecular markers, but for a low number of sampled populations (Breuillin et al., 2006). Consequently, they have precluded any robust conclusions about the level of genetic relatedness among $C$. parasitica isolates, especially relative to Italian isolates, and on recombination processes in Western Europe.

Several biological characteristics of C. parasitica and their interactions with the environment make the study of the reproductive biology of this fungal species a challenging, but fundamental, question in an invasive context. An earlier study suggested reduced outcrossing among divergent genetic lineages within a chestnut stand in France (Dutech et al., 2008). This genetic structure was observed in only one location in France, and may be associated with a recent colonization event. Although both mating types of $C$. parasitica were detected in this studied chestnut stand and more generally in France (Robin et al., 2009), several factors could limit outcrossing in this fungus. First, several observations of selfing were reported in America and in Europe (Marra et al., 2004). Selfing, or better described for C. parasitica as intra-haploid mating (Giraud et al., 2008), occurs in the strains in which both mating types are detected, producing progenies with no segregation for the genetic markers analysed except for the two mating types (McGuire et al., 2004). Thus, multiplication of identical haploid genotypes can be the result of asexual as well as sexual reproduction. Second, C. parasitica can be infected by a double strand RNA virus, the crypho- nectria hypovirus-1 (CHV-1), responsible for the attenuation of the virulence of the fungus, a phenomenon called hypovirulence. The CHV-1 virus is transmitted through hyphal anastomosis between strains with identical or closely related genotypes with vegetative incompatible loci (Cortesi et al., 2001). As the virus causes female sterility of infected strains (Nuss, 2005) and decreases the production of male gametes, CHV-1 is expected to limit sexual reproduction within populations. This virus is wide spread in Europe (Heiniger and Rigling, 1994; Robin and Heiniger, 2001) and could explain a large proportion of the observed genetic structure of C. parasitica populations in this area. Third, environmental factors may influence the outcome of sexual reproduction: for example the production of meiotic spores (ascospores), their dispersal and the chestnut susceptibility to infection by spores, all seem to depend on climatic conditions (Guérin et al., 2001; Guérin and Robin, 2003). The description of the genetic structure of C. parasitica isolates sampled within and among chestnut stands is, therefore, of prime interest to give insight into the mode of reproduction of this introduced plant fungal pathogen in Western Europe.

An earlier study conducted in South of France, where C. parasitica is mainly located and has been established for at least 50 years (Robin and Heiniger, 2001) suggested the occurrence of at least three major genetic lineages associated with three frequent vc types, spatially clustered in the South-Western region, and corresponding to three putative introductions (Robin et al., 2009). Using 10 polymorphic microsatellite loci characterized in earlier studies (Breuillin et al., 2006; Dutech et al., 2008), we investigated the genetic relationships and recombination events among 583 isolates sampled in this part of Western Europe. Our main objectives were (1) to determine the number of divergent genetic pools introduced in France; (2) to assess the frequency of recombination events among these genetic pools and (3) to improve our knowledge of the evolutionary history of introduction of an important invasive fungal plant pathogen.

\section{Materials and methods}

\section{Geographical sampling}

We collected, between 2001 and 2008, pools of 20 to 31 C. parasitica isolates within 20 forest chestnut coppices in South-Western France. For a more extensive view of the genetic diversity in Southern France, three additional pools of isolates were included in the study. They were sampled in 1999 and located in the South-East of the country (a stand composed of an orchard and a neighbouring coppice in Ganges (Breuillin et al., 2006)) and two coppices (Les Mayons and Collobrières). Other details of these 23 geographical groups of isolates such as geographical coordinates are given in Table 1. We did not use the term of 'population' to define these groups of isolates because, as shown in the Results below, these groups were very different from a random reproductive unit, which usually defines a genetic population.

Isolates were obtained from small pieces of bark removed from cankers as described in Robin et al. (2000). Collected material was isolated and cultivated 
Table 1 Geographical coordinates, date of sampling and mating-type ratio of Cryphonectria parasitica isolates collected in the 23 French chestnut stands studied

\begin{tabular}{|c|c|c|c|c|c|c|}
\hline Chestnut stands & Eff & Symbol & Latitude & Longitude & Date & Mating-type ratio $1 / 2 / 1$ and 2 \\
\hline Barcus & 25 & BAR & $43^{\circ} 09^{\prime} 49^{\prime \prime}$ & W $00^{\circ} 49^{\prime} 04^{\prime \prime}$ & 2001 and 2006 & NA \\
\hline Belin-Beliet & 29 & $\mathrm{BBE}$ & $44^{\circ} 31^{\prime} 45^{\prime \prime}$ & W $00^{\circ} 43^{\prime} 49^{\prime \prime}$ & 2006 & $5 / 21 / 2$ \\
\hline Camboulazet & 23 & CAM & $44^{\circ} 13^{\prime} 55^{\prime \prime}$ & E $02^{\circ} 26^{\prime} 56^{\prime \prime}$ & 2008 & $6 / 15 / 2$ \\
\hline Cassaniouze & 26 & CSS & $44^{\circ} 40^{\prime} 47^{\prime \prime}$ & E $02^{\circ} 22^{\prime} 35^{\prime \prime}$ & 2008 & $0 / 19 / 5$ \\
\hline Ceret & 28 & CER & $42^{\circ} 27^{\prime} 35^{\prime \prime}$ & E $02^{\circ} 44^{\prime} 59^{\prime \prime}$ & 2008 & $12 / 12 / 4$ \\
\hline Collonge & 28 & $\mathrm{COL}$ & $45^{\circ} 03^{\prime} 57^{\prime \prime}$ & E $01^{\circ} 39^{\prime} 23^{\prime \prime}$ & 2008 & $2 / 20 / 3$ \\
\hline Espartignac & 28 & ESP & $45^{\circ} 25^{\prime} 08^{\prime \prime}$ & E $01^{\circ} 37^{\prime} 29^{\prime \prime}$ & 2008 & NA \\
\hline Fayet & 28 & FAY & $43^{\circ} 47^{\prime} 37^{\prime \prime}$ & E $02^{\circ} 57^{\prime} 34^{\prime \prime}$ & 2008 & $7 / 0 / 13$ \\
\hline Gabre & 29 & GAB & $43^{\circ} 04^{\prime} 08^{\prime \prime}$ & E $01^{\circ} 25^{\prime} 30^{\prime \prime}$ & 2007 & NA \\
\hline Ganges & 17 & GAN & $43^{\circ} 55^{\prime} 57^{\prime \prime}$ & E $03^{\circ} 42^{\prime} 15^{\prime \prime}$ & 1999 & NA \\
\hline Lairière & 28 & LAI & $43^{\circ} 00^{\prime} 33^{\prime \prime}$ & E $02^{\circ} 29^{\prime} 04^{\prime \prime}$ & 2008 & $9 / 3 / 14$ \\
\hline Laluque & 20 & LAL & $43^{\circ} 51^{\prime} 29^{\prime \prime}$ & W $01^{\circ} 00^{\prime} 11^{\prime \prime}$ & 2007 & NA \\
\hline Montpezat & 23 & MON & $43^{\circ} 30^{\prime} 00^{\prime \prime}$ & W $00^{\circ} 02^{\prime} 43^{\prime \prime}$ & 2001 and 2007 & $1 / 5 / 2$ \\
\hline Rieumes & 24 & RIE & $43^{\circ} 25^{\prime} 28^{\prime \prime}$ & E $01^{\circ} 04^{\prime} 33^{\prime \prime}$ & 2003 and 2006 & NA \\
\hline Salvagnac & 29 & SAL & $43^{\circ} 56^{\prime} 57^{\prime \prime}$ & E $01^{\circ} 43^{\prime} 00^{\prime \prime}$ & 2006 & $0 / 6 / 16$ \\
\hline Sare & 20 & SAR & $43^{\circ} 19^{\prime} 38^{\prime \prime}$ & W $01^{\circ} 33^{\prime} 41^{\prime \prime}$ & 2001 & $9 / 5 / 3$ \\
\hline St Cernin & 30 & STC & $44^{\circ} 40^{\prime} 32^{\prime \prime}$ & E $01^{\circ} 02^{\prime} 16^{\prime \prime}$ & 2005 & $57 / 74 / 8^{\mathrm{a}}$ \\
\hline St Mayme & 29 & MAY & $45^{\circ} 01^{\prime} 23^{\prime \prime}$ & E $00^{\circ} 37^{\prime} 24^{\prime \prime}$ & 2007 & $0 / 18 / 10$ \\
\hline Tesson & 29 & TES & $45^{\circ} 37^{\prime} 18^{\prime \prime}$ & W $00^{\circ} 40^{\prime} 04^{\prime \prime}$ & 2008 & $14 / 12 / 4$ \\
\hline Les Mayons & 13 & LMA & $43^{\circ} 31^{\prime} 03^{\prime \prime}$ & E $06^{\circ} 49^{\prime} 51^{\prime \prime}$ & 1999 & NA \\
\hline Collobrières & 18 & CLB & $43^{\circ} 14^{\prime} 46^{\prime \prime}$ & E $06^{\circ} 19^{\prime} 58^{\prime \prime}$ & 1999 & $0 / 10 / 8$ \\
\hline Vieussan & 31 & VIE & $43^{\circ} 31^{\prime} 42^{\prime \prime}$ & E $03^{\circ} 01^{\prime} 37^{\prime \prime}$ & 2008 & NA \\
\hline Xanthrailles & 28 & XAN & $44^{\circ} 12^{\prime} 35^{\prime \prime}$ & E $00^{\circ} 13^{\prime} 58^{\prime \prime}$ & 2007 & $0 / 15 / 7$ \\
\hline
\end{tabular}

Abbreviations: Eff, effective sampled; NA, not analysed.

Symbols are the references of population used in Figures 1 and 3.

${ }^{\mathrm{a}}$ Data obtained from Dutech et al. (2008).

on potato dextrose agar medium (Difco Laboratories, Detroit) plates in the laboratory.

\section{DNA extraction and genotyping of isolates}

Total DNA was extracted from lyophilized mycelium obtained from cultures on potato dextrose agar plates overlaid with cellophane and ground to a fine powder, according to the method used in Dutech et al. (2008). Isolates were genotyped using 10 microsatellite loci from the C. parasitica genome: I07-650 (Davis et al., 2005), CPE1, CPE3, CPE4, CPE5, CPE8, CPG3, CPG4 (Breuillin et al., 2006), CPG6 and CPG14 (Kubisiak et al., 2007). Loci were amplified and visualized on a CEQ8000 sequencer (Beckman Coulter Inc., 2002) as described in Dutech et al. (2008). Mating type was determined for isolates from 14 of the 23 stands (Table 1) by polymerase chain reaction after the method used in McGuire et al. (2004).

\section{Data analysis}

The number of different multilocus genotypes was estimated using the software Genclone (Arnaud-Haond and Belkhir, 2007). Relationships between the seventh most frequent genotypes in the total sample (see Results) were estimated using the shared allele distance (DAS, Chakraborty and Jin, 1993) and the software Population (Langella, 2002). The number of alleles per locus was estimated within each chestnut stand using the function df2genind in the package ADEgenet (Jombart, 2008) in the statistical software package R v 2.7.1. We assessed whether random sexual reproduction occurred among isolates of one chestnut stand by estimating the index of multilocus linkage disequilibrium $\left(r_{\mathrm{d}}\right)$ implemented in MultiLocus version 2.1 (Agapow and Burt, 2001). This index is based on the index of association $\left(I_{\mathrm{A}}\right)$ defined by Brown et al. (1980), modified to remove dependence on the number of loci (Agapow and Burt, 2001). Departure from the null hypothesis (no linkage disequilibrium; $r_{\mathrm{d}}=0$ ) was assessed by permuting alleles between individuals independently for each locus (1000 permutations), using MultiLocus version 2.1 (Agapow and Burt, 2001). Genetic differentiation among the 23 groups of isolates sampled was estimated by $\theta$ (Weir and Cockerham, 1984) using Genepop software (Raymond and Rousset, 1995).

We tested for the existence of divergent genetic pools of $C$. parasitica in France using two methods: a modelbased Bayesian clustering method (Pritchard et al., 2000; Falush et al., 2003) and genetic multivariate analysis (Jombart et al., 2009) to detect genetically differentiated groups corresponding to independent introductions. These methods avoid the clustering of individuals on a priori knowledge such as geographical locations that may mix divergent genetic lineages introduced in the same area and may hinder the detection of admixture events among these lineages. First, assignment of multilocus genotypes to different clusters was performed using a Bayesian clustering method implemented in the software STRUCTURE V2.2 (Pritchard et al., 2000; Falush et al., 2003). We tested the probability of the admixture model (Falush et al., 2003) for one to eight clusters with data composed of all multilocus genotypes in a single copy, to limit the weight of repeated genotypes in the definition of clusters. Each model was simulated 10 times, with a burn-in of 100000 iterations and a run length of $10^{6}$ iterations after the burn-in. Genetic homogeneity of the clusters was assessed by estimating the proportion of shared alleles within and among clusters and genetic differentiation among clusters by $\theta$ (Weir and Cockerham, 1984). Although STRUCTURE has been used to study genetic relationships among races, cryptic species or to detect regional substructures in 
fungal pathogen species (for example Morgan et al., 2007; Delmotte et al., 2008), violation of hypotheses such as linkage equilibrium in clonal subgroups can sometimes lead to spurious assignments (Falush et al., 2003). We, therefore, used a principal component analysis (PCA) to investigate the genetic structure of the $C$. parasitica population in France. PCA has become a standard tool to describe genetic structure (Jombart et al., 2009). As PCA is independent of any genetic hypotheses such as Hardy-Weinberg equilibrium, it is suitable for the analysis of partially clonal species. PCA analysis was performed using the ADEgenet package (Jombart, 2008) under the R-software. Again, for the PCA analysis, only single copies of the different genotypes were used to give identical weight to multilocus genotypes.

\section{Results}

Out of the 583 isolates analysed, 105 multilocus genotypes were detected using the 10 microsatellite loci. Alleles were confirmed by two independent polymerase chain reactions and genotyping for nearly half of these genotypes, and nearly $75 \%$ of pairs of genotypes differentiated by only one allele were checked by a second polymerase chain reaction. Seven of these multilocus genotypes were observed $>15$ times in several populations (Table 2; Figure 1). The most frequently occurring genotype (RE043) of the study was observed 143 times and was present mainly in the centre of Pyrénées. Two other genotypes (RE028 and RE053) were found mainly in the Atlantic coast (Figure 1). The four other frequently found genotypes (RE019, RE079, RE092 and RE103) were mainly located in the Eastern part of the sampling area. Estimates of shared alleles distance showed that frequent genotypes of the South-West
(RE053, RE043 and RE028) were more closely related than genotypes located in the East (RE079, RE092, RE103), which were clustered together. The last South-East genotype (RE019) was intermediate between these two genetic groups (Figure 1). Composition in alleles for each frequent genotype is given in the Supplementary Table S1.

The number of genotypes within our chestnut stands ranged between 2 and 23 (mean $=7.2$; Table 2), with the highest numbers found in the northern area of sampling (St Mayme, St Cernin, Salvagnac; Table 2). At least one of the seven most frequent genotypes was found in all the stands sampled (Table 2). The sum of their respective frequencies in the stands was always $>50 \%$, except for the central stand of St Mayme and at Tesson on the Atlantic Coast (Figure 1). Allelic richness varied between 1.5 and 4.1 alleles per locus and the richest area was the northern area, as for the number of genotypes (St Mayme, St Cernin, Salvagnac; Table 2). The index of multilocus linkage disequilibrium ranged between 0.18 (St Mayme) and 1.00 (Lairière, Les Mayons), with all estimates significantly different from $0(P<0.01)$, the value expected under random mating. Genetic differentiation among the 23 groups of isolates estimated by $\theta$ was 0.52 , highly significantly different from zero (Fisher's exact test for genetic differentiation $P<0.001$ ). Mating types were determined for 319 out of 583 isolates (54\%) representing 14 out of the 23 chestnut stands analysed in which mating-type 2 was the most frequent mating type observed. In $50.5 \%$ of isolates, only the mat2 allele was amplified, and in 29\%, both mating-type alleles were amplified (Table 2). The two mating types were detected in all sites, either as Mat-homokaryotic or Mat-heterokaryotic isolates.

The posterior probability of the data under the admixture model implemented by STRUCTURE increased steadily

Table 2 Genetic and genotypic diversity of Cryphonectria parasitica sampled in 23 French chestnut stands studied

\begin{tabular}{|c|c|c|c|c|c|c|c|c|c|c|}
\hline Chestnut stands & NbAll & NbGen & RE019 & RE028 & RE043 & RE053 & RE079 & RE092 & RE103 & $R d$ \\
\hline Barcus & 1.7 & 4 & & & 21 & 1 & & & & 0.56 \\
\hline Belin-Beliet & 3.6 & 10 & & 1 & 3 & 17 & & & & 0.49 \\
\hline Camboulazet & 2.4 & 4 & 5 & & & & & & 16 & 0.63 \\
\hline Cassaniouze & 2.6 & 5 & & & & 1 & 22 & & & 0.58 \\
\hline Ceret & 2.3 & 4 & 8 & & 7 & & & 12 & & 0.73 \\
\hline Collonge & 2 & 6 & 1 & & & & 23 & & 1 & 0.63 \\
\hline Espartignac & 2.6 & 9 & & & & 1 & 20 & & 1 & 0.43 \\
\hline Fayet & 1.5 & 3 & 22 & & & & & 5 & & 0.71 \\
\hline Gabre & 1.7 & 3 & & & 26 & & & & & 0.94 \\
\hline Ganges & 1.4 & 5 & 1 & & & & & 9 & & 0.37 \\
\hline Lairière & 1.7 & 2 & & & 26 & & & & & 1.00 \\
\hline Laluque & 2.8 & 9 & & 6 & 6 & 2 & & & & 0.52 \\
\hline Montpezat & 1.6 & 4 & & & 19 & 2 & & & & 0.83 \\
\hline Rieumes & 3.9 & 7 & 1 & 1 & 18 & & & & & 0.55 \\
\hline Salvagnac & 3.6 & 16 & 8 & & 2 & & 3 & 2 & 2 & 0.28 \\
\hline Sare & 2.7 & 10 & & 3 & 1 & 7 & & & & 0.48 \\
\hline St Cernin & 4.1 & 15 & 2 & & 2 & 2 & 13 & & & 0.51 \\
\hline St Mayme & 4.1 & 23 & 3 & & 1 & & 2 & 3 & & 0.18 \\
\hline Tesson & 3.2 & 9 & & & & 11 & & & & 0.55 \\
\hline Les Mayons & 1.4 & 2 & 12 & & & & & 1 & & 1.00 \\
\hline Collobrières & 1.6 & 5 & 4 & & & & & 5 & & 0.36 \\
\hline Vieussan & 1.5 & 6 & 8 & & & & & 6 & & 0.37 \\
\hline Xanthrailles & 3.6 & 6 & & 5 & 11 & 6 & & & 4 & 0.67 \\
\hline
\end{tabular}

NbAll, mean number of alleles per locus.

NbGen, observed number of different genotypes.

$\mathrm{Rd}$, index of multilocus linkage disequilibrium (Agapow and Burt, 2001).

RE019, RE028, RE043, RE053, RE079, RE092 and RE103 are the labels of the seven most frequent genotypes observed in the study. 


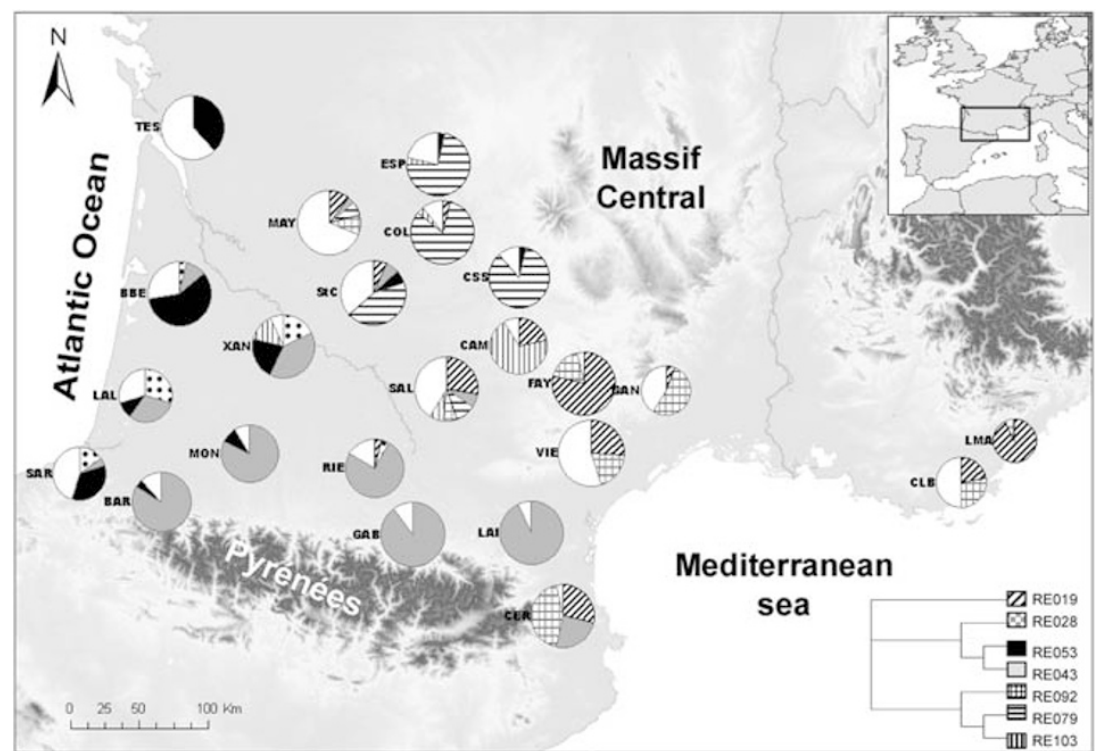

Figure 1 Geographical distribution of the 23 chestnut stands sampled and frequencies of the seven most frequent genotypes observed in the study (RE019, RE028, RE043, RE053, RE079, RE092, RE103) for each stand. White parts are frequencies of the other less frequent genotypes. At the bottom right, genetic relatedness among the seven most frequent genotypes represented using the distance alleles shared and the unweighted pair group method with arithmetic mean (UPGMA) classification.

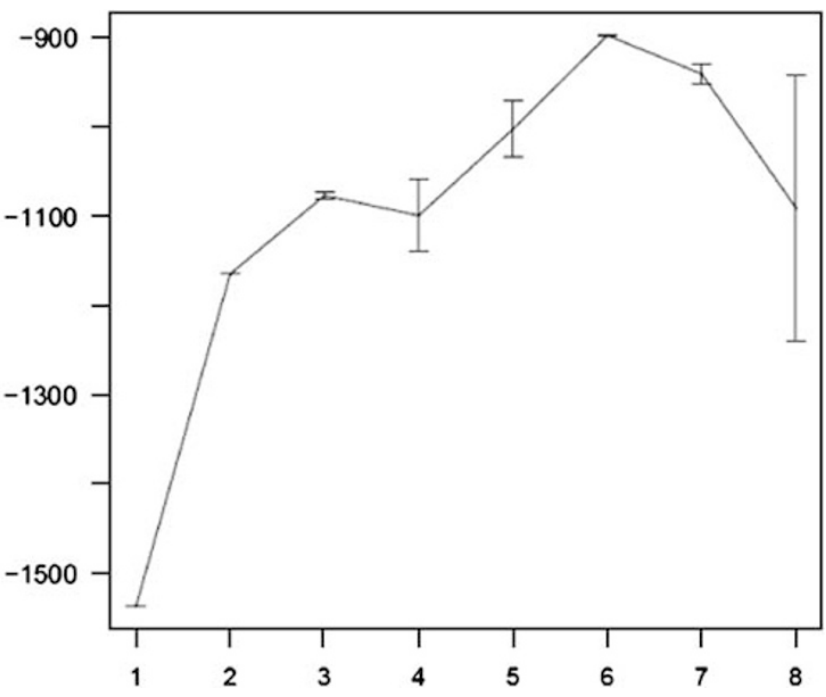

Figure 2 Change of the posterior probability of the model estimated by the software STRUCTURE (Pritchard et al., 2000) according to the number of genetic clusters K ( 1 to 8$)$ tested and performed on the 105 different $C$. parasitica multilocus genotypes observed in the 23 French chestnut stands analysed. Standard deviation of the posterior probability was obtained on 10 iterations for each number of clusters tested.

until three clusters (Figure 2). The optimum number of clusters to represent our data seemed to be $K=3$ because of the decrease in variation in posterior probability values obtained above three clusters, the increase of the standard deviation obtained for the 10 iterations (Figure 2) and also the probabilities of assignment to four clusters, which were generally smaller than for those given for three clusters (data not shown). This choice was also motivated to avoid the definition of spurious genetic clusters without biological explanation
(Pritchard et al., 2000). A threshold for the probability of assignment equal to 0.85 was then defined to assign genotypes to the three different clusters. Forty-five genotypes, including the four frequent genotypes RE019, RE079, RE092 and RE103, were, therefore, clustered in one cluster (C1), which was mainly located in the Eastern part of the sampling area (Figure 3). A second cluster (C2) was composed of 20 genotypes mainly located in the Western part and genetically close to the genotypes RE043 and RE053. The third cluster (C3) grouped the least frequent genotype RE028 and 11 other genotypes, all located near Pyrénées (Figure 3). However, the homogeneity of this last cluster may be questionable because the mean shared alleles distance was high (0.72) compared with groups $\mathrm{C} 1$ and C2 (0.45 and 0.35, respectively). The minimum mean shared alleles distance among the three clusters was 0.82 (between $\mathrm{C} 1$ and C3). The index of association $\left(r_{\mathrm{d}}\right)$ for $\mathrm{C} 1$, C2 and C3 was 0.06, 0.05 and 0.33, respectively, and all were significantly different from $0(P<0.01)$. Genetic differentiation between $\mathrm{C} 1$ and $\mathrm{C} 2$ was 0.53 , and between C3-C1 and C3-C2 was 0.37 and 0.38, respectively. All these estimates were significantly different from zero (Fisher's exact test for genetic differentiation, $P<0.001$ ). Twenty-eight of the genotypes (5\% of isolates) were not assigned to any cluster. These genotypes were mainly located on the coastal area (Sare, Laluque and BelinBeliet; Figure 3) and in the central part of the sampling area (St Cernin, St Mayme and Salvagnac; Figure 3). When the model with four clusters was tested in STRUCTURE, the cluster C2 was split into two: RE053 and several related genotypes in one group, and RE043 and the rest of the genotypes in the other one. The composition of the two other clusters stayed almost unchanged.

A PCA clearly separated two groups of genotypes on the first axis (Figure 4). One group with positive coordinates on the first axis (PC1) was composed of the 


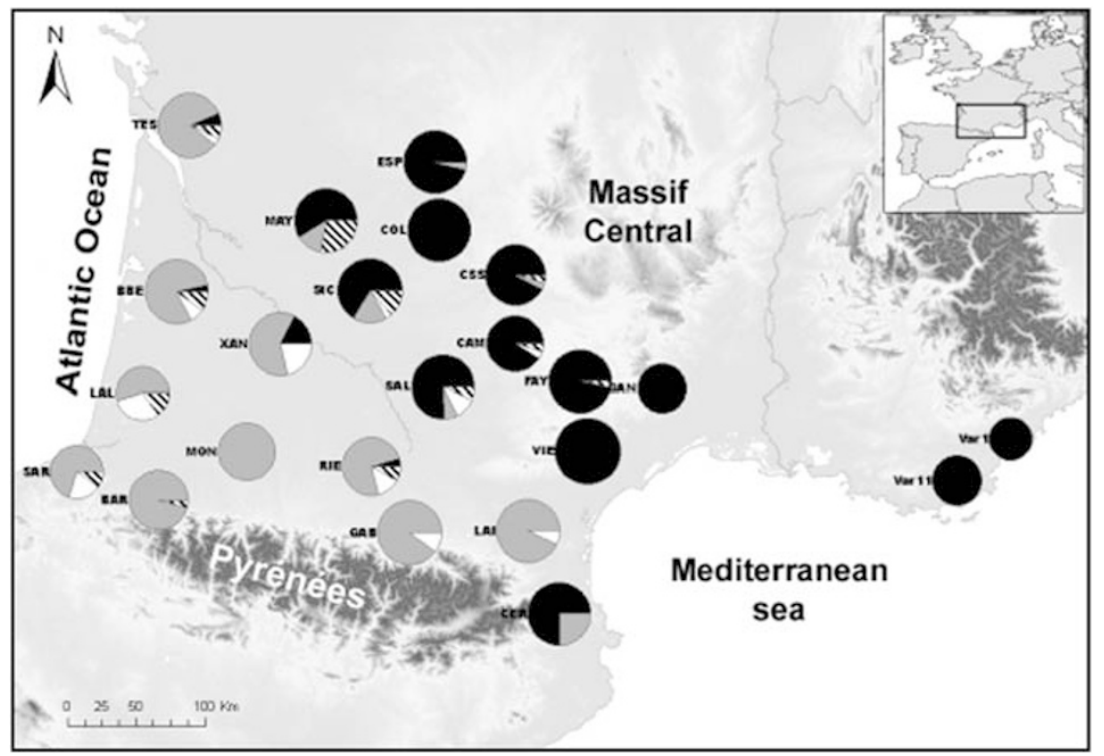

Figure 3 Geographical distribution of the C. parasitica isolates assigned to the three genetic groups inferred by STRUCTURE (see text for details). Groups C1, C2 and C3 are represented in black, grey and white, respectively. Unassigned isolated to these three groups are represented with stripes.

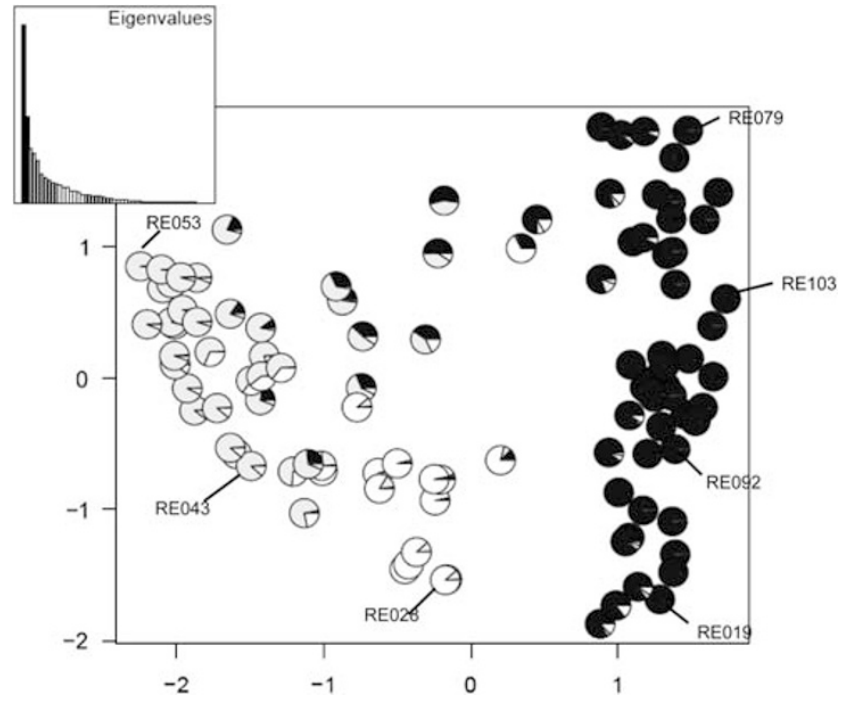

Figure 4 Coordinates of the 105 different $C$. parasitica genotypes sampled within 23 French chestnut stands on the two main axes of the PCA. Pie charts give the probability of assignment for each genotype to the three genetic clusters tested by STRUCTURE (groups C1, C2 and C3 are represented in black, grey and white, respectively).

genotypes located in the Eastern part of the sampling area (that is isolates of the cluster C1 defined by STRUCTURE) and the other group was composed of all the other genotypes mainly located near Pyrénées (that is C2 and C3 clusters) (Figure 4). The second axis of the PCA (PC2) was less discriminating. However, genotypes more closely related to the Western genotype RE028 had higher negative values on PC2 than most of the genotypes assigned to C2 (Figure 4). The third axis obtained from the PCA analysis gave no interpretable information (data not shown), and its Eigen value was nearly half of that in the second axis (Figure 4).
The relative contributions of the two first axes to the total genetic variation were 25.1 and $12.2 \%$, respectively, whereas the third was $7.7 \%$. Eight genotypes intermediate between the groups C1 and C2 (that is with a PCA coordinate close to zero on the first axis and a positive coordinate on the second axis) were observed (Figure 4).

\section{Discussion}

The main result of this study was the characterization of at least three divergent genetic pools with a low number of intermediate genotypes among these pools. Assuming that the geographical distribution of genotypes is not or little explained by selective effects, the detection of three differentiated and spatially clustered genetic pools strongly suggests several events of introduction, which have taken place during the last century in France. The first genetic pool, including the genotypes RE019, RE079, RE092 and RE103, may be partly associated with an Italian introduction occurring before the first report of the disease in 1938 near Genoa (Biraghi, 1946). The spatial distribution of the frequent genotypes RE019 and RE092 mainly located in the Eastern part of the sample was in agreement with isolates migrating from Italy, and expanding to the North and the West in France (Robin and Heiniger, 2001). Indeed, these two genotypes were detected at high frequencies in several chestnut stands near Torino in Italy (Rostagno, 2009) and were generally associated with the dominant vc types in South-Eastern France, Northern Italy and Southern Switzerland (that is EU-2 and EU-5; Robin and Heiniger, 2001; Cécile Robin, unpublished data). However, the strong clustering of RE079 in the Northern part of the sampling area and of RE103 in the central part might be due to non-Italian introductions of $C$. parasitica in these geographical areas. A more intensive genetic analysis of South-Eastern France should confirm this hypothesis.

The two other genetic pools (one closely related to RE028 and the other to RE043 and RE053) were mainly 
located near Pyrénées. The strong geographical clustering of the two dominant genotypes RE043 and RE053 on the Atlantic coast and in the central part of Pyrénées, respectively, suggested two independent introductions in South-Western France. Similarly, the main coastal distribution of RE028 and the spatial clustering in Central Pyrénées of a few rare isolates genetically close to RE028 were also in agreement with two independent introductions, which have mixed infrequently until now. It is unlikely that the group C3 defined by STRUCTURE and associated to RE028 is a spurious group because of high linkage disequilibrium among loci (Falush et al., 2003). According to Falush et al. (2003), when STRUCTURE estimates spurious groups, all probabilities of assignment to these groups are low. In our study, 11 genotypes were strongly assigned to $C 3(P>0.85)$, and a high level of genetic differentiation was estimated between the two other genetic clusters. These results confirmed that gene flow between C3 and the two other groups has been limited until now. These two introductions supported by the two genetic groups C2 and C3 and separating the coastal area and the centre of Pyrénées were also suggested by the analysis of vc types in 19 French chestnut stands in which $C$. parasitica occurred (Robin et al., 2009). Introductions of Asian chestnuts (Castanea crenata and C. mollissima, from Japan and China, respectively) were reported in Pyrénées (Darpoux, 1949). Several of these trees were imported because they were reputed to be resistant to the ink disease caused by Phythophthora cinnamomi and P. cambivora. These trees could have introduced the chestnut blight disease in this area and might have initiated chestnut blight foci in France long before the first official description of the disease in Europe, in 1938 in Italy (Darpoux, 1949). The detection of identical vc types in Spain as in the SouthWestern France (Robin et al., 2009) was congruent with this hypothesis, which nevertheless should be confirmed by genotyping Spanish isolates. Similar introductions of Asian chestnuts near Massif Central (Schad et al., 1952) could also explain the geographical clustering of RE079 and RE103 in the northern and central part of this study, respectively.

Our results also revealed that sexual reproduction between divergent gene pools was infrequent. Only a few genotypes could be interpreted as intermediate genotypes among the three main clusters: only a few isolates had PCA coordinates between those located on the left and on the right of the first axis, and only $5 \%$ of isolates could not be assigned by STRUCTURE to the three clusters, despite a high cutoff threshold used to assign genotypes. Most of these intermediate genotypes were observed in the regions in which two or three divergent genetic pools co-occurred (Figure 3). This spatial distribution suggested that low genetic recombination among these genetic pools was mostly because of the history of introductions. The geographical isolation of the main areas of introduction (that is Pyrénées and Italy) and the low levels of gene flow suggested by the high genetic differentiation among geographical groups of C. parasitica (see also Breuillin et al., 2006) in agreement with the slow expansion of the disease in Europe (Robin and Heiniger, 2001) might have limited genetic admixture among the three divergent genetic pools until recently. Fragmentation of the host population (C. sativa) in France may also represent a strong barrier to gene flow for C. parasitica, as sexual and asexual spores were assumed to mainly disperse short distances of only a few hundred meters (for example Milgroom and Lipari, 1995; Dutech et al., 2008).

Within stands, we also observed a low recombination rate among genotypes: there were few genotypes different from the seven most dominant genotypes and large genetic disequilibrium. This result is surprising, as the two mating types allowing sexual reproduction among genotypes were generally detected in most of chestnut stands sampled. For example, if RE019 and RE092 from the same genetic cluster C1 were recombining freely in the South-Eastern stands analysed, we would expect 16 different combinations of the four distinct alleles (Supplementary Table S1), but we only observed a maximum of six different genotypes at Vieussan. For more stands, we confirmed the results obtained from a spatial genetic analysis at St Cernin, where few recombination events among the dominant genotypes were detected (Dutech et al., 2008). Founding events from a single genotype and spatial clustering of identical genotypes as observed in St Cernin (Dutech et al., 2008) probably favoured asexual reproduction in the first steps of colonization of the stands and inbreeding reproduction in a second step. However, the large geographical distribution of RE019 and RE092 detected in most of South-Eastern stands, as well as RE053 and RE028 in most of Atlantic stands, suggests an ancient presence of these genotypes in these areas. This ancient presence is also in agreement with the official presence of C. parasitica reported in 1956 in the South-Eastern France (Grente, 1981) and assumed before 1940 in Pyrénées (Darpoux, 1949), and the presence of vc types EU-2 and EU-5 associated with RE019 and RE092, and detected at least since 1970 in South-Eastern France (Robin et al., 2000; Cécile Robin, unpublished data). Furthermore, sexual structures were observed in France for $>30$ years (Grente, 1981), regularly detected in neighbour countries (Switzerland and Italy; for example Milgroom and Cortesi, 1999), and observed on 10 to $20 \%$ of cankers sampled in two French chestnut stands (Guérin et al., 2001; Cécile Robin, unpublished data). As sexual structures suggest the potential for recombination, we must assume that founding events have an impact for long time periods (that is tens of years) or that other causes explain the low frequencies of recombinant genotypes within these stands. First, we cannot exclude that the effects of the CHV-1 virus causing female sterility of the infected strains (Nuss, 2005) promotes asexual spores as the main vectors of colonization of the disease within and among the stands. Viral infections have been detected in most chestnut stands in France (Robin and Heiniger, 2001), and its presence could strongly limit sexual reproduction among isolates. Second, infection of hosts by ascospores may also be limited because of climatic conditions or other environmental conditions as shown by Guérin et al. (2001) for production and ascospore dispersal. Third, dominant genotypes could be characterized by increased fitness above that of recombinant genotypes because of more advantageous interactions with the different viral lineages observed in Europe (Gobbin et al., 2003) and/ or with host genotypes. Studies on interactions with the hypovirus CHV-1 have been performed on only a few examples, but they have showed significant differences 
in fitness components among viral-fungus combinations (for example Peever et al., 2000). These stimulating results call for such experiments with French C. parasitica and $\mathrm{CHV}-1$ genotypes.

In conclusion, this study illustrates the complexity of the spatial pattern of genetic diversity in an invasive fungal pathogen. It shows that $C$. parasitica isolates sampled within French chestnut stands cannot be considered as belonging to a panmictic population, because of the low recombination rate among the most frequent genotypes. Our results stand in contrast to those obtained in studies of invasive plants, for which multiple introductions generally offer the opportunity of frequent recombination among divergent genotypes, contributing to their invasive success (for example Dlugosch and Parker, 2008). In fungi, such a low recombination rate among close genetic lineages despite the presence of compatible mating types has also been reported in several invasive Phytophthora species (cited in Goss et al., 2009). Further studies are required to conclude on the importance of this phenomenon during fungal biological invasions, but limited genetic admixture among independent introductions could be frequent in invasive species alternating sexual and asexual reproduction as suggested for clonal plant species (Barrett et al., 2008). Another question that remains for $C$. parasitica is whether the genetic lineages were preadapted to French environmental conditions or whether few recombination events occurred in the first steps of introduction to produce genotypes adapted to the novel environment. Contrasted results were obtained on invasive plant and insect species (see for example Lavergne and Molofsky, 2007; Peccoud et al., 2008). A comparison between native Asian genotypes and the frequent French genotypes should provide helpful insights into the evolutionary processes that have occurred during the invasion of $C$. parasitica in Europe.

\section{Conflict of interest}

The authors declare no conflict of interest.

\section{Acknowledgements}

We thank J Lemoine for assistance in the field, and $\mathrm{M}$ Martin, F Hubert and C Chomeau for assistance in the laboratory. We also thank F Delmotte, F Halkett, $\mathrm{P}$ Gladieux and S Prospero for helpful discussion and comments on the manuscript, and Sophia Ahmed and Everett Hansen for English corrections and useful comments. This project was supported by grants from INRA (Département Santé des Plantes et Environnement and Département Ecologie des Forêts, Prairies et milieux Aquatiques: Projet Epidémiologie et dynamique des populations), from ITT-CTP2000-4, from CTP (Pyrénées Work Community) and from Agence National pour la Recherche ANR 07-BDIV-003 (Emerfundis project).

\section{References}

Agapow PM, Burt A (2001). Indices of multilocus linkage disequilibrium. Mol Ecol Notes 1: 101-102.

Anagnostakis SL (1987). Chestnut blight-the classical problem of an introduced pathogen. Mycologia 79: 23-37.
Arnaud-Haond S, Belkhir K (2007). GENCLONE: a computer program to analyse genotypic data, test for clonality and describe spatial clonal organization. Mol Ecol Notes 7: $15-17$.

Barrett SCH, Colautti RI, Eckert CG (2008). Plant reproductive systems and evolution during biological invasion. Mol Ecol 17: 373-383.

Barton NH (2001). The role of hybridization in evolution. Mol Ecol 10: 551-568.

Biraghi A (1946). Il cancro del castagno causato da Endothia parasitica. Ital Agric 7: 1-9.

Braganca H, Simoes S, Onofre N, Tenreiro R, Rigling D (2007). Cryphonectria parasitica in Portugal: diversity of vegetative compatibility types, mating types, and occurrence of hypovirulence. For Pathol 37: 391-402.

Breuillin F, Dutech C, Robin C (2006). Genetic diversity of the chestnut blight fungus Cryphonectria parasitica in four French populations assessed by microsatellite markers. Mycol Res 110: 288-296.

Brown AHD, Feldman MW, Nevo E (1980). Multilocus structure of natural populations of Hordeum spontaneum. Genetics 96: 523-536.

Chakraborty R, Jin L (1993). Determination of relatedness between individuals using DNA-fingerprinting. Hum Biol 65: 875-895.

Cornman RS, Burke JM, Wesselingh RA, Arnold ML (2004). Contrasting genetic structure of adults and progeny in a Louisiana iris hybrid population. Evolution 58: 2669-2681.

Cortesi P, McCulloch CE, Song HY, Lin HQ, Milgroom MG (2001). Genetic control of horizontal virus transmission in the chestnut blight fungus, Cryphonectria parasitica. Genetics 159: 107-118.

Darpoux H (1949). Le chancre du châtaignier causé par l'Endothia parasitica. Ministère de l'Agriculture, Document Phytosanitaire No 7.

Davis JE, Kubisiak TL, Milgroom MG (2005). Polymorphic sequence-characterized codominant loci in the chestnut blight fungus, Cryphonectria parasitica. Mol Ecol Notes 5: 195-197.

Delmotte F, Giresse X, Richard-Cervera S, M'baya J, Vear F, Tourvieille J et al. (2008). Single nucleotide polymorphisms reveal multiple introductions into France of Plasmopara halstedii, the plant pathogen causing sunflower downy mildew. Infect Genet Evol 8: 534-540.

Desprez-Loustau ML, Robin C, Buee M, Courtecuisse R, Garbaye J, Suffert F et al. (2007). The fungal dimension of biological invasions. Trends Ecol Evol 22: 472-480.

Dlugosch KM, Parker IM (2008). Founding events in species invasions: genetic variation, adaptive evolution, and the role of multiple introductions. Mol Ecol 17: 431-449.

Dutech C, Rossi JP, Fabreguettes O, Robin C (2008). Geostatistical genetic analysis for inferring the dispersal pattern of a partially clonal species: example of the chestnut blight fungus. Mol Ecol 17: 4597-4607.

Engelbrecht CJB, Harrington TC, Steimel J, Capretti P (2004). Genetic variation in eastern North American and putatively introduced populations of Ceratocystis fimbriata $f$. platani. Mol Ecol 13: 2995-3005.

Facon B, Jarne P, Pointier JP, David P (2005). Hybridization and invasiveness in the freshwater snail Melanoides tuberculata: hybrid vigour is more important than increase in genetic variance. J Evol Biol 18: 524-535.

Falush D, Stephens M, Pritchard JK (2003). Inference of population structure using multilocus genotype data: linked loci and correlated allele frequencies. Genetics 164: 1567-1587.

Giraud T, Yockteng R, Lopez-Villavicencio M, Refregier G, Hood ME (2008). Mating system of the anther smut fungus Microbotryum violaceum: selfing under heterothallism. Eukaryot Cell 7: 765-775. 
Gobbin D, Hoegger PJ, Heiniger U, Rigling D (2003). Sequence variation and evolution of Cryphonectria hypovirus 1 (CHV-1) in Europe. Virus Res 97: 39-46.

Goodwin SB, Cohen BA, Fry WE (1994). Panglobal distribution of a single clonal lineage of the Irish potato famine fungus. Proc Natl Acad Sci USA 91: 11591-11595.

Goss EM, Carbone I, Grunwald NJ (2009). Ancient isolation and independent evolution of the three clonal lineages of the exotic sudden oak death pathogen Phytophthora ramorum. Mol Ecol 18: 1161-1174.

Grente J (1981). Les variants hypovirulents de $1^{\prime}$ Endothia parasitica et la lutte biologique contre le châtaignier. $\mathrm{Ph}$. Thesis, Université de Bretagne Occidentale, Brest, France.

Guérin L, Froidefond G, Xu XM (2001). Seasonal patterns of dispersal of ascospores of Cryphonectria parasitica (chestnut blight). Plant Pathol 50: 717-724.

Guérin L, Robin C (2003). Seasonal effect on infection and development of lesions caused by Cryphonectria parasitica in Castanea sativa. For Pathol 33: 223-235.

Heiniger U, Rigling D (1994). Biological-control of chestnut clight in Europe. Annu Rev Phytopathol 32: 581-599.

Jombart T (2008). adegenet: a $\mathrm{R}$ package for the multivariate analysis of genetic markers. Bioinformatics 24: 1403-1405.

Jombart T, Pontier D, Dufour AB (2009). Genetic markers in the playground of multivariate analysis. Heredity 102: 330-341.

Kubisiak TL, Dutech C, Milgroom MG (2007). Fifty-three polymorphic microsatellite loci in the chestnut blight fungus, Cryphonectria parasitica. Mol Ecol Notes 7: 428-432.

Langella O (2002). Populations 1.2.28 Software. CNRS UPR 9034: France.

Lavergne S, Molofsky J (2007). Increased genetic variation and evolutionary potential drive the success of an invasive grass. Proc Natl Acad Sci USA 104: 3883-3888.

Liu YC, Milgroom MG (2007). High diversity of vegetative compatibility types in Cryphonectria parasitica in Japan and China. Mycologia 99: 279-284.

Marra RE, Cortesi P, Bissegger M, Milgroom MG (2004). Mixed mating in natural populations of the chestnut blight fungus, Cryphonectria parasitica. Heredity 93: 189-195.

McGuire IC, Marra RE, Milgroom MG (2004). Mating-type heterokaryosis and selfing in Cryphonectria parasitica. Fungal Genet Biol 41: 521-533.

Milgroom MG, Lipari SE (1995). Spatial analysis of nuclear and mitochondrial RFLP genotypes in populations of the chestnut blight fungus, Cryphonectria parasitica. Mol Ecol 4: 633-642.

Milgroom MG, Cortesi P (1999). Analysis of population structure of the chestnut blight fungus based on vegetative incompatibility genotypes. Proc Natl Acad Sci USA 96: 10518-10523.

Milgroom MG, Sotirovski K, Spica D, Davis JE, Brewer MT, Milev M et al. (2008). Clonal population structure of the chestnut blight fungus in expanding ranges in southeastern Europe. Mol Ecol 17: 4446-4458.
Montenegro D, Aguin O, Sainz MJ, Hermida M, Mansilla JP (2008). Diversity of vegetative compatibility types, distribution of mating types and occurrence of hypovirulence of Cryphonectria parasitica in chestnut stands in NW Spain. For Ecol Manage 256: 973-980.

Morgan JAT, Vredenburg VT, Rachowicz LJ, Knapp RA, Stice MJ, Tunstall T et al. (2007). Population genetics of the frogkilling fungus Batrachochytrium dendrobatidis. Proc Natl Acad Sci USA 104: 13845-13850.

Novak SJ (2007). The role of evolution in the invasion process. Proc Natl Acad Sci USA 104: 3671-3672.

Nuss DL (2005). Hypovirulence: mycoviruses at the fungal-plant interface. Nat Rev Microbiol 3: 632-642.

Peccoud J, Figueroa CC, Silva AX, Ramirez CC, Mieuzet L, Bonhomme $\mathrm{J}$ et al. (2008). Host range expansion of an introduced insect pest through multiple colonizations of specialized clones. Mol Ecol 17: 4608-4618.

Peever TL, Liu YC, Cortesi P, Milgroom MG (2000). Variation in tolerance and virulence in the chestnut blight fungushypovirus interaction. Appl Environ Microbiol 66: 4863-4869.

Pritchard JK, Stephens M, Donnelly P (2000). Inference of population structure using multilocus genotype data. Genetics 155: 945-959.

Raboin LM, Selvi A, Oliveira KM, Paulet F, Calatayud C, Zapater MF et al. (2007). Evidence for the dispersal of a unique lineage from Asia to America and Africa in the sugarcane fungal pathogen Ustilago scitaminea. Fungal Genet Biol 44: 64-76.

Raymond M, Rousset F (1995). An exact test for population differentiation. Evolution 49: 1280-1283.

Robin C, Heiniger U (2001). Chestnut blight in Europe: diversity of Cryphonectria parasitica, hypovirulence and biocontrol. For Snow Landsc Res 76: 361-367.

Robin C, Anziani C, Cortesi P (2000). Relationship between biological control, incidence of hypovirulence, and diversity of vegetative compatibility types of Cryphonectria parasitica in France. Phytopathology 90: 730-737.

Robin C, Capdevielle X, Martin M, Traver C, Colinas C (2009). Cryphonectria parasitica vegetative compatibility type analysis of populations in south-western France and northern Spain. Plant Pathol 58: 527-535.

Rostagno L (2009). Interaction between Cryphonectira parasitica and CHV1: a model for virus caused hypovirulence. $\mathrm{Ph}$ Thesis, Università degli studi di Torino XXI ciclo.

Schad C, Solignat G, Grente J, Venot P (1952). Recherches sur le châtaignier à la Station de Brive. Annales de l'Amélioration des plantes III: $376-458$.

Silvertown J (2008). The evolutionary maintenance of sexual reproduction: evidence from the ecological distribution of asexual reproduction in clonal plants. Int J Plant Sci 169: 157-168.

Stukenbrock EH, Banke S, McDonald BA (2006). Global migration patterns in the fungal wheat pathogen Phaeosphaeria nodorum. Mol Ecol 15: 2895-2904.

Weir BS, Cockerham CC (1984). Estimating F-statistics for the analysis of population structure. Evolution 8: 1358-1370.

Supplementary Information accompanies the paper on Heredity website (http://www.nature.com/hdy) 